Rapid Automatic Naming Predicts More than Sublexical Fluency:

Evidence from English-French Bilinguals

\author{
Robert Savage ${ }^{1,2}$, Miriam McBreen², Fred Genesee ${ }^{2}$, Caroline Erdos ${ }^{3}$, \\ Corinne Haigh ${ }^{4} \&$ Aishwarya Nair ${ }^{2}$ \\ ${ }^{1}$ UCL Institute of Education* Corresponding author \\ Psychology and Human Development \\ 25 Woburn Square \\ London \\ United Kingdom \\ WC1H 0AA \\ Robert.savage@ucl.ac.uk \\ ${ }^{2}$ McGill University Montreal \\ ${ }^{3}$ Montreal Children's Hospital \\ ${ }^{4}$ Bishop's University
}




\begin{abstract}
Rapid Automatized Naming is an important predictor of reading fluency. Whether Rapid Automatized Naming measures abstract sublexical correspondence fluency (Theory A) or word-specific fluency (Theory B) is unresolved. English, and to a lesser extent, French orthographies are opaque for reading. Thus, if Rapid Automatized Naming predicts word reading fluency after controlling for within-language pseudoword decoding fluency, in typical English-French bilingual students, theory B is supported over theory A. Hierarchical regression analyses with 76 typical English-French bilingual students revealed that kindergarten Rapid Automatized Naming predicted English word and French word reading fluency in Grade 6 and sometimes in Grade 3 after within-language pseudoword reading fluency was controlled, supporting theory B. However, Rapid Automatized Naming consistently predicted French word and pseudoword reading, supporting theory A. We argue that Rapid Automatized Naming indexes resources for learning both the lexical features of written words and orthography-tophonology correspondences in opaque orthographies among bilingual students.
\end{abstract}

Keywords: Rapid Automatized Naming, reading, orthographic depth, consistency, bilingualism 


\section{Rapid Automatized Naming Predicts More than Sub-Lexical Fluency: Evidence from English-French Bilinguals}

\subsection{Introduction}

Rapid Automatized Naming (RAN) tasks, which assess the ability to name a seriallypresented list of letters, words, colors or objects as rapidly as possible, are important predictors of later reading ability (e.g., Norton \& Wolf, 2012). However, what mediates this RAN-reading relationship remains contentious. One well-established path to understanding RAN and its contribution to reading is to assess RAN's predictive power in languages that vary in orthographic depth, typically carried out with monolingual speakers of each language. In the present study, we extended this logic to a group of students educated in both English and French, providing a natural experiment to explore the cross-linguistic role of RAN in two languages often viewed as having deep orthographies, in the same learners. Because the participants were learning both languages in the same broad familial, cultural and scholastic contexts and with the same general constitutional resources (educational history, context, intelligence, attention, general language abilities, broad dispositional and motivation factors, for example), issues of sample comparability that can bedevil cross-linguistic comparisons using different participants are much reduced, if not eliminated, in our study. Below we first consider theories of the role of RAN in English and then across languages to underpin the present study.

\subsection{Early predictors of reading ability}

Numerous studies have shown that knowledge of grapheme-to-phoneme correspondence (GPCs) along with phonemic awareness (PA) strongly predict reading ability in English (Bond \& Dijkstra, 1967; Lervåg, Bråten, \& Hulme, 2009). RAN tasks have also 
been strongly implicated in reading development. In typically developing children, reliable longitudinal correlations between scores on both alphanumeric and non-alphanumeric RAN measures and reading ability have frequently been reported (Bowey, 2005; Kirby, Georgiou, Martinussen, \& Parrila, 2010; Lervåg \& Hulme, 2009; Wolf \& Bowers, 1999).

\subsection{Theories of the relationship between $\mathrm{RAN}$ and reading}

Theories of RAN abound. RAN has sometimes been theorized as a measure of general resources that impact reading - such as processing speed (Kail, Hall, \& Caskey, 1999), visual processing (Stainthorp, Stuart, Powell, Quinlan, \& Garwood, 2010), or serial processing ability (Georgiou, Parilla, Cui, \& Papadopoulos, 2013). According to these conceptualizations, RAN reflects general reading-related processing skills and, thus, should not exhibit language-specific effects. Another class of theories sees RAN as tapping subprocesses intimately involved in reading. Below we describe two such theories. Some such models construe RAN as a measure of the efficiency of the use of GPCs or other sub-lexical Orthography-to-Phonology Correspondence (OPC) units (e.g. Manis, Seidenberg, \& Doi, 1999), a view that we term Theory A.

Broadly consistent with Theory A, Savage, Pillay, and Melidona (2007) deconstructed the components of RAN in 65 below-average readers and spellers by first analyzing the factorial associations between RAN tasks, pseudoword decoding and a range of processing speed and speeded response measures that required the inhibition of a dominant response (e.g. rapidly naming ' 1 ' as ' 2 ' and vice versa, in number lists). In preliminary factor analyses, all RAN speeded naming tasks uniquely loaded together as a Rapid Naming factor. A second factor - labelled Alphanumeric Naming, clustered all tasks involving speeded alphanumeric naming and included RAN and all other response speed and speeded inhibition tasks. Finally, 
alphanumeric RAN tasks loaded with pseudoword decoding as a third factor labeled-Decoding. A second wave of analyses explored the unique associations of these three process latent variables with reading. After chronological age, non-verbal ability and the Decoding factor were first entered, the Alphanumeric Naming factor predicted less than $2 \%$ of the unique variance and the Rapid Naming factor predicted less than $1 \%$ of the unique variance in word reading. The Decoding factor explained $50 \%$ of the unique variance in word reading. These results suggest that among poor readers, RAN operates on reading primarily through its association with phonological decoding ability, consistent with Theory A above.

Also consistent with Theory A, Moll, Fussenegger, Willburger, and Landerl, (2009) note that RAN was as strong a predictor of pseudoword as of real word reading fluency in German students. Moll et al. ran concurrent stepwise regression analyses with 3 samples of monolingual German children (sample 1: $n=342$, sample 2: $n=640$ sample 3: $n=247$ ). After controlling for chronological age at step 1 and pseudoword reading fluency at step 2 in each sample, they report that RAN explained only $0.05 \%$ and $0.07 \%$ of unique variance in word reading fluency in the first two (larger) samples and $1.7 \%$ of unique variance in the last sample. Arguably, these analyses would benefit from the inclusion of more complete controls (e.g. general verbal ability, phonological awareness, reading accuracy), including controls for the nestedness of data in their large samples. Nevertheless, overall, less than $1 \%$ of unique variance was explained by the specific RAN-word reading fluency association across more than 1000 children. A coherent interpretation of Moll et al.'s data is that RAN primarily underpins the automation of sub-lexical processes that are then used in the fluent reading of both words and pseudowords. 
Alternatively, RAN has been viewed as an index of word-specific 'orthographic' and/or word-specific phonological knowledge (Bowers \& Wolf, 1993; Decker, Roberts, \& Englund, 2013; Powell, Stainthorp, \& Stuart, 2014); we term this broad view Theory B ${ }^{\mathrm{i}}$. Theory B suggests that RAN taps into a mechanism by which known words are directly and rapidly retrieved from the mental lexicon. Here, RAN has been viewed as a measure of rapid access to lexical phonological representations - verbal labels for words stored in long-term memory (Clarke, Hulme, \& Snowling, 2005; Wagner \& Torgesen, 1987). From this broad view, RAN predicts reading because the integrity and efficiency of the network involved in mapping objects to their verbal labels may place constraints on the development of a written word-recognition system (Lervåg \& Hulme, 2009). The findings that RAN and PA explain independent variance in reading ability, that low correlations are sometimes found between RAN and phonological measures, and that some individuals exhibit reading difficulties despite intact phonological processing arguably suggests that a strongly phonologicallymoderated theory of RAN may not be accurate and, thus, provides indirect support for Theory B (Bowers, 1993; Georgiou, Manolitsis, Nurmi, \& Parrila, 2010; Savage \& Frederickson, 2005).

RAN also probably taps distinct processes related to lexical access and, thus, text reading fluency (Bowers, 1993; Georgiou et al., 2010; Savage \& Frederickson, 2005; Young \& Bowers, 1995). Savage and Frederickson (2005) found that RAN, but not PA, explained unique variance in passage reading fluency after controlling for passage reading accuracy, suggesting that RAN assesses ongoing word retrieval efficiency during passage reading. Theory B is also supported by evidence from meta-analytic reviews that RAN-reading associations are stronger in languages where orthography-to-phonology patterns are less 
consistent (Araújo, Reis, Petersson, \& Faísca, 2015) and where, on some views, lexical information may be required to resolve pronunciation ambiguities (Schmalz, Marinus, Coltheart, \& Castles, 2015). The role of language consistency is considered further below.

\subsection{Crosslinguistic modulation of RAN}

Alphabetic languages vary in orthographic transparency - the degree of correspondence they exhibit between graphemes and phonemes (e.g., Caravolas \& Bruck, 1993; Caravolas et al., 2012). English is a morpho-phonological language and is, thus, considered a 'deep' orthography. It is at the 'opaque' end of the language orthographic transparency-consistency spectrum and has been labeled an 'outlier orthography' (Share, 2008). In the most transparent languages, such as Finnish, which exhibit an almost one-to-one correspondence between graphemes and phonemes (Georgiou, Parrila, Kirby, \& Stephenson, 2008; Ibrahim, 2015), almost all readers achieve reading accuracy rapidly (Caravolas, 2005; Everatt \& Zabell, 2002; Harris \& Hatano, 1999; Seymour et al., 2003). In such highly transparent orthographies, the most persistent reading difficulties are related to reading speed, and RAN is often the main cognitive deficit observed in children with dyslexia (Landerl \& Wimmer, 2000; Wimmer, 1993; Wimmer, Mayringer, \& Landerl, 1998). There also exists evidence from direct comparative studies that RAN predicts reading across a range of European spelling systems but that the relationship is partly moderated by orthographic consistency (Araújo et al., 2015; Vaessen et al, 2010; Zielger et al., 2010).

There has been some debate about the orthographic transparency of French. It has been asserted that French, unlike English, has relatively high 'feed-forward' consistency from graphemes to phonemes, but similarly low "feed-back" consistency from phonemes to graphemes (Moll et al., 2009, 2014). French is generally not, however, accepted to be a 
'transparent' orthography (Borgwaldt, Hellwig, \& de Groot, 2005; Caravolas, 2005;

Seymour, Aro, \& Erskine, 2003; Ziegler et al., 2010). For example, Seymour et al.'s comparative study reported French as the European language closest to English in terms of orthographic depth and Ziegler et al. reported similar patterns based on calculated 'entropy' values of initial consonants. In such analyses, if a letter always corresponds to one phoneme, its entropy value is zero, and the higher the entropy value, the larger the number of alternate pronunciations of an onset letter. Ziegler et al. report that the entropy value of French is .46 which is the next highest after English with .83, compared to .00 for Finnish, .17 for Hungarian, and .23 for Dutch. This debate may reflect, in part at least, the impact of the specific measures used to assess opacity, such as vowel consistency (Moll et al., 2009) versus onset entropy (e.g. Ziegler et al., 2010), where these two indices give somewhat different measures of relative opacity, particularly for French (Borgwaldt et al., 2005). Schmalz, et al. (2015), argue that the opacity of languages is multifaceted, reflecting orthographic complexity (for example, in English, the number of clusters such as th and $s h$ ), consistency (e.g. multiple pronunciations of '-ough' in words), and completeness (the existence of heterophonic homographs such as 'wind'). Schmalz et al. argue on this basis that some current estimates of opacity underestimate linguistic depth. French, for example, has relatively higher complexity (many complex GPC rules) even than English in their data. Undoubtedly, readers of French also frequently encounter orthographic inconsistencies such as silent letters or letter combinations such as "-ent" in the plural verb "marchent"(they walk) or "-s" in "chats" (cats) and must learn not to pronounce them in some but not other lexical and grammatical contexts (e.g. "le vent" versus "ils dansent", respectively). There also exist a number of high frequency words that embody exceptions to standard phonic rules in French 
(e.g. "sept", "huit", “dix", “gentil”, “femme”, “août”, “est”, “oignon”). Schmalz et al. term this latter case of exception word processing, orthographic 'unpredictability', a feature shared by English and French. Theory B suggests that RAN indexes this 'unpredictability'.

Theoretical accounts A and B of the relationship between RAN and reading described earlier provide differential predictions for its precise role in languages that vary in orthographic depth. A strong version of the theoretical view of RAN as a measure of rate of access to GPCs and/or other OPCs (Theory A) would predict that RAN is more strongly related to word and pseudoword reading in more transparent orthographies, such as German, than in less transparent orthographies, such as English, because an automated recoding strategy based on a relatively limited number of phonic rules will be effective for fluent reading of most or all words and pseudowords in a transparent orthography (Furnes \& Samuelsson, 2011; Share, 1995; Snowling \& Hulme, 1994; Torgesen, Wagner, Rashotte, Burgess, \& Hecht, 1997). This prediction has been verified empirically (e.g., in German as described earlier, by Moll et al., 2009; and in Dutch by van den Boer, de Jong, \& Haentjensvan Meeteren, 2013). Importantly, German and Dutch are both more transparent than either English or French. This transparency may explain the weak RAN-word reading relationship observed in German and Dutch after controls for pseudoword reading. On the assumption that French and English are both relatively opaque, then Theory A would predict the same degree of correlation between RAN on the one hand and word and pseudo-word reading on the other hand in both English and in French.

It is important to clarify that the reasoning behind Theory A does not assume that lexical representations are less evident in transparent than in opaque orthographies per se. Theory A does not directly speak to that matter at all although, as noted earlier, Theory A is 
entirely consistent with a view that fluent sub-lexical representations come to underpin accurate stored representations of words in the lexicon. Rather, Theory A states that the degree of shared automated sub-lexical processing involved in both word and pseudoword reading, and as theorized, indexed by RAN, is somewhat larger in transparent over opaque orthographies. Theory A can thus explain why RAN predicts word and pseudoword reading fluency outcomes within languages, and (in a general sense at least) the existence of RANreading associations across orthographies of varying degrees of opacity (Araújo et al., 2010).

\subsection{The Present Hypotheses}

This theoretical perspective leads to testable predictions. If the predictions from either theory A or B hold longitudinally after controls for the autoregressor of initial reading ability, such links may have causal status (e.g. Savage et al., 2004; Wagner et al., 1997). It is these longitudinal claims that are thus addressed here. If RAN specifically measures abstract sublexical GPC / OPC knowledge (a strong version of Theory A), then RAN should not appreciably predict word reading fluency longitudinally after controlling for pseudoword reading fluency. On the assumption that French and English are both opaque, similar patterns should be obtained in both reading systems. On the other hand, unique longitudinal prediction of word reading fluency is posited from a strong version of Theory B that RAN measures distinct aspects of lexical processing such as 'unpredictability' (Schmalz et al. 2015), evident in opaque orthographies such as English. Given the general consensus that French also behaves as an opaque orthography, Theory B predicts that RAN should also longitudinally predict word reading fluency after controlling for pseudoword reading fluency in French. These hypotheses are tested in the present study among native English-speakers taking part in early French immersion school programs (described in more detail in section 2.3). 
Specifically, these bilingual students provide the opportunity to compare the contributions of RAN to predicting reading in two opaque orthographies: English and French, while controlling for all within-child factors (Patel, Snowling, \& de Jong, 2004). Such studies offer natural experiments with a high degree of control allowing more precise comparisons of language effects. To our knowledge, no such studies have been undertaken to date to explore the role of RAN in reading.

In this study, data were collected at several points over a 7-year period for multiple purposes of examining crosslinguistic relationships in reading (Haigh, Savage, Erdos, \& Genesee, 2011; 2014). Although collected for a study designed for multiple purposes, these data permitted us to explore the extended time-course and developmental patterns evident in RAN-reading associations. Some studies have reported diminishing RAN-reading developmental links over grades (Torgesen, Wagner, \& Rashotte, 1997; Wagner et al., 1997) or a time-limited or task- or risk-status limited effect (Savage, 2004). Others report that RANreading associations remain constant (Kirby, Parrilla, \& Pfeiffer, 2003; Landerl \& Wimmer, 2008) or even increase across grades (Cardoso-Martins \& Pennington, 2004). A meta-analysis conducted by Araújo et al. (2015) suggests that correlations between RAN and reading accuracy decrease across grades, while correlations between RAN and reading fluency remain constant. In addition to variations in empirical findings, longitudinal RAN-reading links have arguably often been imperfectly theorized. Using a longitudinal design is apt in the present context insofar as it has been argued that it may take up to six years for students to acquire full proficiency in a second language (Cummins, 1981). If second language (L2) RAN and reading fluency depend upon broader L2 language proficiency, longitudinal RAN-reading 
links up to Grade 6 are particularly important to assess. Differential predictions for Theory A and $\mathrm{B}$ are:

1. Theory A: RAN should not longitudinally predict word reading after controlling for pseudoword decoding.

2. Theory B: RAN should longitudinally predict word reading after controlling for pseudoword decoding in English and French, assuming English and French are both opaque orthographies.

\subsection{Method and Materials}

\subsection{Design}

The study used a seven-year longitudinal design. Five control measures (receptive vocabulary, non-verbal reasoning, early word reading and letter-name knowledge, phonological awareness, chronological age) were all administered in English and in French in the spring of kindergarten alongside four predictor measures (four tests of RAN in English and four in French); an expressive vocabulary test was administered in the fall of kindergarten. In the fall of Grades 2, 3, and 6, tests of word and of pseudoword reading fluency were administered to all available participants. Parts of this dataset have been reported in some previous studies addressing other issues (e.g. Erdos, Genesee, Savage, \& Haigh, 2014; Haigh, Savage, Erdos, \& Genesee, 2011). Data on RAN are reported here for the first time.

\subsection{Participants}

A valid human participants ethics certificate was first obtained from McGill University for all of this research. Following school board and school approval, consent letters were then sent out to all parents of children in the relevant grades in five schools. The 
obtained sample consisted exclusively of children for whom parental consent had been obtained and included two cohorts of English-dominant kindergartners in schools located in a suburb outside of Montreal, Canada, and initially included 115 students (86 from cohort 1 and 29 from cohort 2) with normal hearing and normal or corrected visual capacities. Over the study, 39 participants were lost to attrition for reasons including, for example, moving to a new school, or not renewing consent to participate in the study for the next school year. The final sample included 76 children $(62.34 \%$ female, Mean age in the fall of kindergarten $=$ 65.84 months, $\mathrm{SD}=3.62$ ). Statistical contrasts of the remaining 76 children and the 39 who left the study showed no significant differences on baseline (kindergarten) measures of vocabulary and general intellectual ability: the Peabody Picture Vocabulary Test (PPVT-IIIA; Dunn \& Dunn, 1997), $t(115)=1.297, p=.257$; and Raven's Coloured Progressive Matrices (RPCM; Raven, Raven, \& Court, 1998), $t(114)=1.727, p=.191$ or on any of the eight RAN tests administered $t(114)<1.5, n . s$. in all cases. Thus, there was no evidence of selective longitudinal experimental mortality of participants.

Students came from five elementary schools that offered early total French immersion programs and included monolingual English speakers or students whose dominant language was English despite some exposure to French outside school. All kindergarten and grade 1 instruction, including literacy teaching, was provided in French, their L2. English was introduced in grade 2 for $15 \%$ of instruction time and was gradually increased up to $70 \%$ in grade 6. Earlier research on similar early total immersion programs in the same community as the present study have shown that English-speaking students in these programs attain the same levels of English language competence as similar students in all-English programs. They also exhibit comparably advanced levels of functional proficiency in French, including 
literacy. This proficiency is such that it permits these students to take advanced secondary school level courses in physics and history, for example, in French (Genesee, 2004).

Information about the students' parents' education was obtained from a questionnaire. Results were compared with Canada's 2011 census information regarding the highest level of education for females and males aged 25-54. This relationship was analyzed using an $X^{2}$ analysis for goodness of fit. This revealed that the mothers and fathers in our sample were more likely to have a post-secondary school education / diploma or technical training and less likely to hold a university degree than national norms, $X^{2} 2(N=76)=28.11$, and 21.78, $p$ $<.001$ for mothers and for fathers, respectively.

\subsection{Materials and Procedure}

\subsubsection{Control measures administered in kindergarten.}

With the exception of an experimental phonological awareness measure, all tests were published tools selected because they have established reliability and validity and are widely used in the field. Published reliabilities of all tests are presented in Table 2.

Non-verbal intelligence. The Raven's Coloured Progressive Matrices is a test of nonverbal intelligence (Raven et al., 1998). The test is made up of sixty untimed perceptual problems in five sets of 12 items.

Vocabulary. English receptive vocabulary was assessed using the Peabody Picture Vocabulary Test - IIIA (PPVT-IIIA; Dunn \& Dunn, 1997). The French version, called the Échelle de Vocabulaire en Images Peabody (EVIP; Dunn, Thériault-Whalen, \& Dunn, 1993) is an independently standardized adaptation of an older English version, the Peabody Picture Vocabulary Test-Revised (PPVT-R; Dunn \& Dunn, 1981). 
Word Reading. English word reading ability was assessed using the word reading subtest of the Wide Range Achievement Test-3 (WRAT-3; Wilkinson 1993), which includes letter naming (15 items) and word reading (55 progressively more difficult words). The French version is a direct translation of the WRAT-3 and was administered identically to the English version. Letters named in English on the French version were scored as errors as were letters named in French on the English test (Haigh et al., 2011).

Phonological awareness. Phonological awareness was assessed using experimental English and French blending tasks. This test was selected as it provided a pure measure of phoneme blending. Two to three phonemes were orally presented in consonant-vowel (t-ea), vowel-consonant (ea-t) or consonant-vowel-consonant (b-ea-t) patterns, and the child was asked to blend them to generate a word. Each test contained nine items. This test has been shown to have good predictive validity in comparable bilingual samples (Haigh et al., 2011).

\subsubsection{Predictor measures administered in kindergarten.}

Rapid Automatic Naming. Four subtests of the English version of the Rapid Automatized Naming and Rapid Alternating Stimulus Tests (RAN/RAS; Wolf \& Denckla, 2005) were administered. The RAN/RAS test includes six subtests in total; we administered the four assessing RAN (RAN objects, RAN colors, RAN numbers, RAN letters). Students are asked to name a serially presented list of stimuli as quickly as possible and are scored on time required to name all the stimulus items. Subtests were only administered if the child could correctly name the five practice items of each subtest. Participants made few errors (percent error: English $M=1.12, S D=2.74$; French $M=1.35, S D=3.66$ ). In the French assessment, the same four RAN/RAS subtest plates were administered and participants simply responded to the items in French. 


\subsubsection{Outcome measures administered in Grades 2, 3, and 6.}

Word and pseudoword reading fluency. Students were given the English and French versions of the Test of Word Reading Efficiency (TOWRE; Torgesen, Wagner, \& Rashotte, 1999). The TOWRE was selected for the present study because it is a standardized measure of phonological decoding and sight word reading accuracy and fluency. A French adaptation of the English TOWRE, developed by Jared, Cormier, Levy, and Woolley (2011) was used to assess French fluency. French words had a similar structure to the English words, in terms of number of letters and syllable structure, and French words were matched for complexity with the English words. The French version of the TOWRE contained some items that would be incorrect if pronounced using English spelling-sound correspondences, so it captured specific knowledge of French spelling-sound correspondences. In both language versions, the TOWRE includes a word component that involves reading real words and a pseudoword component that involves decoding pseudowords. Each participant was shown a list of progressively more complex and lower frequency words and separately, a list of pseudowords, and asked to name as many items as they could within 45 seconds in each case. The score consisted of the total number of correct words.

\subsection{Results}

\subsection{Preliminary data analysis}

Prior to the main analyses, evaluation of the four primary assumptions of hierarchical regression was performed for each individual regression (i.e., linearity and colinearity, independence of observations, normality, and equality of variances). For all hierarchical regressions, standard assumptions were met. One outlier was found for the French TOWRE words component in Grade 6 and that outlier was set to the next lowest value. Missing data 
made up $4.8 \%$ of the data set in our final longitudinal sample. Preliminary ANOVA analyses confirmed that the 'missing' status of data was not systematically related to the fluency outcomes in grade 6. We then imputed missing data using the MVA program within SPSS. Finally, we undertook all analyses with and without missing data. These produced identical patterns of statistical significance for all analyses. As a result, all analyses presented below are based on the imputed data set with 76 participants, and all analyses are thus directly comparable in size.

Given that some of the French tests were adaptations of English versions, only raw scores were available and used in the analyses. Table 1 presents correlations for English predictor and English outcome measures and for French predictor and French outcome measures. Table 2 presents means, standard deviations, and test internal reliabilities for the same measures. The following general patterns emerged across both languages: Receptive vocabulary (PPVT) was related to certain tests of reading fluency (TOWRE); blending ability was correlated with reading accuracy (WRAT) and fluency (TOWRE); RAN subtests were correlated amongst themselves within and across languages; and TOWRE scores in each language at different time points were correlated among themselves at the same times. RAN scores in each language were also correlated with performance on the corresponding TOWRE subtests at all time points. Scores on the English RAN objects, RAN numbers and RAN letters were correlated with all TOWRE measures in English, whereas English RAN colors was correlated only sometimes. For French RAN subtests, all subtests were correlated with French TOWRE outcomes.

Given the links between word reading, phonological awareness, verbal and non-verbal ability and both RAN and reading fluency evident in the tables, all control measures were first 
controlled as a group statistically when analyzing RAN's impact on reading fluency. Prior to inferential analyses, Exploratory Factor Analysis with Varimax rotation was applied to the four English and four French RAN data sets separately in order to reduce the data. This yielded clear single latent variable factor solutions that we used as a proxy for the English and French RAN data separately; in both cases, this latent variable explained over $80 \%$ of the variance in naming. These two latent variables were then used as predictor variables in subsequent regression analyses for English and French fluency outcomes.

\subsection{Hierarchical regressions}

In order to examine the relationship between RAN and reading fluency in each language, two-step hierarchical regressions were first performed separately for English and French dependent variables, each with their respective same language predictor and control variables. TOWRE word and pseudoword fluency measures in each language were first considered as outcome measures at each of Grades 2, 3 and 6 for English and French separately. Corresponding same-language kindergarten control variables of word reading and letter name knowledge, phonological blending, chronological age, vocabulary in each language and Raven's matrices scores were entered together at step 1 in each case. The corresponding same-language RAN latent variable measure was then entered as a predictor measure at step 2 .

In order to assess whether RAN contributed to word reading scores above and beyond abstract GPC and other OPC relationships (i.e., the claim in Theory B that RAN measures lexical processing), additional three-step hierarchical regressions were performed for English and French, separately. In these analyses, TOWRE pseudoword reading fluency in each 
language was entered at step 2 and TOWRE word reading fluency was entered as an outcome variable at step 3; the same control variables as above were entered together at step 1.

In the regression analyses presented in Tables 3 and 4, omnibus summary statistics for the combined effects of all control variables entered simultaneously at step 1 are presented to aid economy and clarity of reporting the results. Ranges for variations in $r^{2}$ are thus provided alongside $p$-values for all step 1 results in Tables 3 and 4. Table 3A presents all hierarchical regressions for the English RAN latent predictor variable and English pseudoword reading outcome. All 2-step and 3-step regressions for English TOWRE word reading fluency are presented in sections $\mathrm{B}$ and $\mathrm{C}$, respectively, of Table 3. Table 4A presents all hierarchical regressions for the French RAN latent variable and French pseudoword reading. All 2-step and 3-step regressions predicting French TOWRE word reading are presented in sections B and $\mathrm{C}$ respectively of Table 4 .

English pseudoword reading. RAN was a non-significant unique predictor of pseudoword reading fluency at step 2 at every grade explaining between 2.2 and $3.6 \%$ of unique variance in Grades 2, 3, and 6.

English word reading. RAN was a significant unique predictor of reading fluency in Grades 3 and 6 at step 2, without controlling for pseudoword reading explaining between 3.6 and $10.4 \%$ of unique variance in Grades 2, 3, and 6. In the 3-step model, controlling for pseudoword reading fluency at step 2, RAN remained a significant unique predictor explaining $3.7 \%$ of unique variance in Grade 6.

French pseudoword reading. RAN was a significant predictor of reading fluency at step 2 in Grades 2, 3, and 6 explaining between 6.7 and $8.2 \%$ of unique variance. 
French word reading. In all grades, RAN was a significant predictor of word reading fluency at step 2 explaining between 8.7 and $11.7 \%$ of unique variance in Grades 2, 3, and 6 . In the 3-step model, which controlled for French pseudoword reading fluency at step 2, RAN remained a significant predictor of word reading fluency in Grades 3 and 6 explaining 3.6\% of unique variance in grade 6.

As a further empirical test of the specificity of the RAN-reading link, we assessed RAN's cross-linguistic predictive importance using English predictor and French outcome measures. It might be argued that any difference in results between French and English reflects the fact that English reading attainment was measured in an L1 and where earlier reading proficiency may thus obtain. If correct, this view predicts that English RAN should predict French reading fluency in the same manner as it predicts English reading fluency. If however, English and French RAN both predict French reading fluency in a similar way this suggests that any differences such as the absolute level of early ability in RAN in English (L1) and French (L2) cannot explain any language-specific pattern of reported effects of RAN on reading fluency. Parallel analyses to those already reported were thus run with English kindergarten predictors of French outcomes. The results of these analyses are depicted in Table 5.

English predictors and French pseudowords. Results showed that the English RAN latent variable was a predictor of French pseudoword reading fluency at step 2 explaining between 3.7 and $6 \%$ of unique variance across grades. This effect reached significance in Grade 2. As reported above, English RAN predicted only around 1\% of English pseudoword fluency across grades and never reached significance. 
English predictors and French words. In the key 3-step model, controlling for extraneous variables at step 1 and French pseudoword reading fluency at step 2, the English RAN latent variable explained no appreciable unique variance in word reading in Grades 2 or 3. In Grade 6 it explained $4.4 \%$ of unique variance, an effect that just escaped conventional significance. As reported above, these patterns are very similar to those reported in our corresponding analyses for English and French words with same-language predictors.

\section{Discussion}

The present research sought to compare the importance of RAN in predicting reading fluency in French and English, which are both generally viewed as having opaque orthographies. It was predicted from Theory A that if RAN only measures abstract GPC/OPC fluency then it should not predict word reading fluency in either language once pseudoword reading fluency has been controlled statistically and outcome correlations should be the same in both English and French. In contrast, from Theory B, if RAN measures other more wordspecific learning, RAN should predict word reading in French and English even after controlling for pseudoword reading in the respective languages.

Our sample consisted of English-French bilinguals who were followed from Kindergarten to Grade 6 in a bilingual program. The longitudinal design of the study using a single cohort of children learning to read in both French and English thus provided insights into the longitudinal predictive effects of RAN while naturally controlling for many general within-child factors (e.g., attention, experience, general within-child constitutional and dispositional factors etc) and other extraneous variables, although the absolute levels of performance of the participants on all tasks reflect the L1 and L2 status of English and French, respectively, in this sample. 
In English, RAN was not a significant predictor of pseudoword reading fluency but was a significant predictor of English word reading fluency in Grades 3 and 6 after controls for numerous extraneous variables. This relationship remained significant even after controlling for pseudoword reading fluency in Grade 6, explaining $3.7 \%$ of unique variance. Taken together, the findings that RAN made some specific contribution to predicting word reading fluency in English in Grade 6 in analyses controlling for pseudoword reading fluency along with the poor predictive power for RAN on pseudoword reading fluency tasks in the 2step analyses of English suggest that RAN may tap processes beyond GPC/OPC fluency in English, as an L1 as predicted by Theory B. Such processes may be those involved in lexical retrieval of known words in line with evidence that, indeed, RAN taps the retrieval of known words from the mental lexicon (Furnes \& Samuelsson, 2011; Manis et al., 1999; Wolf \& Bowers, 1999).

In contrast, RAN was a significant predictor of both word reading and pseudoword reading fluency in French in all grades even after controlling for pseudoword decoding fluency. RAN accounted for $11 \%$ and $3.6 \%$ of unique variance in the reading outcome measures beyond that explained by pseudoword reading in Grades 3 and 6 respectively. Taken together, these results for French lend support for the conceptualization of RAN as being a measure of fluency of GPC/OPC (Theory A) as well as a measure of lexical retrieval in French (Theory B), at least when considered as an L2 (Furnes \& Samuelsson, 2011; Share, 1995; Torgesen et al., 1997).

How might the results from the analyses of these two languages be interpreted more broadly? Neither Theory A nor B alone is able account fully for both the English L1 and the French L2 data in our study. On the one hand, Theory B garners support from the English and 
French results insofar as RAN predicted word reading fluency even after controlling for pseudoword reading fluency. On the other hand, Theory A garners some support from the finding of consistent strong association between RAN and both word and pseudoword reading fluency in French at all ages tested. As a result, we suggest that a broader conceptualization of RAN is possibly needed than is currently found in some models. We hypothesize that rather than seeing RAN as a 'fixed' predictor of the mastery of certain elements of orthographic and phonological processing in the acquisition of reading fluency, at least in dual language contexts where both languages exhibit some opacity, it is perhaps best seen as an index of a learning capacity that adapts to reflect the underlying orthographic structures of two distinct spelling systems.

Any statistical learning mechanism used for reading in dual language learners presumably reflects a capacity to adapt to the distinct additional challenges of acquiring reading fluency in an L2 over the monolingual case. We cannot entirely disentangle opacity from the dual language context of English and French here. It may be that RAN indexes a capacity that is used flexibly when the L2 shares opacity with the L1 but also has somewhat different orthographic structures than the L1, and when proficiency in L2 reading, while advanced, may still be developing. In this regard, we note, however, that Morfidi, van der Leij, de Jong, Scheltinga, and Bekebrede, (2007) provide evidence that RAN in L1 Dutch (a substantially less opaque orthography) also predicts L2 English reading, suggesting RAN is predictive across L1 and L2 systems varying in opacity.

Based on these findings, we hypothesize that RAN is a relatively general orthographic learning resource that facilitates the acquisition and mastery of both the lexical-level patterns required to read the opaque orthography of English as an L1 and the numerous complex 
GPC/OPC associations and word-specific associations required to become a fluent reader of the deep orthography of French as an L2. Put another way, RAN assesses the ability to link letters and sounds at a variety of grain sizes including the whole word. Such a broad view of RAN might potentially also facilitate explanations of the apparent universality of RAN-reading fluency associations in other research that implicates different languages. For example, as noted earlier, there is good evidence of highly specific associations between RAN with GPC/OPC fluency in highly transparent orthographies such as German (Moll et al., 2009) and also in alphabetic systems varying in opacity (Araújo et al., 2015; Vaessen et al., 2010; Zielger et al., 2010). At the same time there exists evidence of a reliable link between RAN and Chinese character reading fluency (Song, Georgiou, Su, \& Hua, 2016). By extrapolation, the learning capacities indexed by RAN are responsive to the particular task demands of a given orthography or in the case of bilingual education systems - orthographies. It is also possible that relative levels of vocabulary knowledge affect the strength of the RAN-reading association, in that when vocabulary is weaker there is less use of word knowledge to 'cleanup' partially accurate phonological representations in an L2, though the relative consistency of the cross-linguistic RAN-reading associations reported above argue against this. Exploration of L1 and L2 reading acquisition in contexts where orthographic depth can be contrasted more clearly could however elucidate exactly how flexible the deployment of processes indexed by RAN can be. Recently, for example, Lallier, Acha, and Carreiras (2016) have provided evidence that the acquisition of an L1 orthographic system can engender qualitatively distinct influences in L2 task learning depending on the opacity of the L1 system. Explorations of the role of RAN in such contexts may be highly fruitful in further understanding the full extent of RAN-reading links in dual language contexts. 
Developmentally, our data suggest that for English at least, the use of a readingrelated learning resource linked to orthographic/phonological processing, as indexed longitudinally by kindergarten RAN, may only become evident in later grades and especially Grade 6, once students have a more fully developed mental lexicon. It may be for this reason that our findings differ from studies showing no strong RAN involvement in tasks measuring orthographic processing in younger children (e.g. Jared, Cormier, Levy, \& Wade-Woolley, 2013). The Jared et al. study also involved children making lexical decisions about letter strings in pseudowords rather than, as here to read words and pseudowords out loud, which may also have influenced their findings. The finding of a link between RAN and reading in grade 6 reported here may reflect a developmental phase where alphabetic representations within words are 'consolidated' (Ehri, 2005). In Ehri's model, consolidation involves the integration of a diverse range of knowledge sources in fluent word reading (for example, including morphological knowledge sources), whereas our data only speak to those most likely tapped by RAN. However, there is not agreement on the developmental picture - a number of researchers have reported that RAN is a more important predictor of fluency in early reading acquisition (Compton, 2003; Georgiou, Parrila, \& Kirby, 2006; Meyer, Wood, Hart, \& Felton, 1998; Schatschneider, Fletcher, Francis, Carson, \& Foorman, 2004) while others have found the relationship becomes stronger over time (Cardoso-Martins \& Pennington, 2004; Vaessen et al. 2010). Further research is needed to elucidate RAN's longterm predictive ability. We should also note here that our analyses are in many senses both highly conservative and highly specific. We report significant effects from kindergarten over 7 years, controlling for numerous within-child factors. This level of control allowed us to explore precisely theory-driven RAN-word reading fluency associations longitudinally and 
across languages in bilinguals that go beyond the profuse patterns of associations between RAN and word and pseudoword reading evident in our simple correlations in both English and French. More longitudinal work of exactly this kind is nevertheless needed.

While it was noted in the Introduction that there exists a link between RAN and reading across orthographies such as English, French, and German, there is also clear evidence to indicate that RAN may be differentially involved in processes related to reading in different languages (Araújo et al., 2015). This finding is corroborated by the somewhat distinct patterns of associations we found between RAN and fluency in French and English. In more transparent languages, such as German, where phonological processing linked to GPC/OPC use is a broadly effective strategy, evidence suggests that RAN may primarily assess fluency of sublexical processing used in word and pseudoword reading (e.g. analyses in Moll et al., 2009). However, in more opaque orthographies such as English and French, our data suggest that RAN may instead (or more probably, additionally) tap into lexical retrieval of phonological and /or orthographic information in 'unpredictable' exception words or words with high orthographic inconsistency. Such processes appear to emerge relatively late in development in grade 6 . The specific pattern of associations we observed between RAN and word reading fluency both in English and in French do not lend themselves readily to alternative and more general theoretical explanations of RAN as a measure of broad speeded, visual or serial processing (Georgiou et al., 2013; Kail et al., 1999; Stainthorp, et al., 2010). The general demands of speed, visual processing and seriality are shared in both the word and pseudoword reading fluency tasks. Thus, our findings in English and in French that significant longitudinal RAN-word reading fluency associations remain after controls for 
pseudoword fluency argue against these more general theoretical explanations of RANreading associations.

There are a number of limitations of the present study. First, attrition of participants in the present study may have limited internal validity, although statistical contrasts indicated no evidence of selective longitudinal experimental mortality of participants. Our sample differed from the national average in terms of parental education. We thus caution that it is unknown whether these results generalise to more nationally representative samples. The study is arguably modestly powered, with three variables in the stepwise regressions and with $n=76$ cases. This design gives an IV/DV ratio that is generally considered acceptable, and which was sufficient to identify small significant effects. As well, the participants' proficiency in English-L1 and French-L2 may have differed from child to child depending on their home situation or the greater total amount of time devoted to French over English in school, which may potentially have impacted the results. The participants may have been learning to read English and French at different rates, and at any given point may have been reading in qualitatively different ways in their L1 and L2; this in turn may have influenced the results. However, high correlations were generally found between French and English reading accuracy - scores on the English and French versions of the WRAT were correlated $.592(p<.001)$ and fluency scores on the English and French versions of the TOWRE across grades were correlated between the ranges of .731 ( $p<$ $0.001)$ and $.880(p<0.001)$ across Grades 2 to 6 , suggesting there were not major issues in terms of overall relative levels of ability in L1 and L2.

A related concern could be how relative levels of kindergarten performance affect the outcomes reported across English and French. For the autoregressor (WRAT reading), a 
number of kindergarten children could not read a single word or identify candidate letters in French but were able to decode a substantial number of words or letter names in English $(M=$ 0.26; $S D=1.21$ in French vs. $M=11.30 ; S D=5.23$ in English). Thus, there is variability for the Kindergarten English but not the French reading measures. This difference could potentially explain why RAN predicts pseudoword reading fluency in French but not in English after controlling for early reading skills. If this were true, one would expect very different results across languages, but for the most theoretically important 3-step analyses controlling for pseudoword reading fluency, the results are very similar for English and French. When we ran additional analyses using the English Kindergarten measures as predictors at step 1 in regression analyses for French outcomes at steps 2 and 3, overall, the patterns for word and pseudoword reading at steps 2 and 3 were very similar to those using the French kindergarten controls and reading autoregressor. For the key 3-step analysis controlling for pseudoword fluency, for example, RAN predicted $4.4 \%$ of unique variance in French word reading fluency in Grade 6 versus 3.6\% of unique variance in parallel analyses with the French autoregressor.

Since we assessed RAN only once, we cannot assess concurrent RAN-reading changes as some cross-sectional designs have sought to do. Such analyses are methodologically complementary to our work. Moreover, the unique linguistic and educational characteristics of the present sample mean that these results cannot automatically be generalized to other contexts directly. Results may also reflect the particular points at which children were assessed. More generally, replication of patterns reported here across other dual language contexts and samples and in monolingual samples learning to read in similar languages is advisable. 
In sum, we argue that in bilingual contexts and with opaque orthographies, RAN is a complex measure of multiple reading sub-processes. Future investigations that compare RAN-reading links in languages that are more clearly at opposite ends of the transparency spectrum (e.g., English and Russian) and that also use measures of text reading fluency, as well as more studies that assess the long-term predictive power of RAN in either scenario would contribute significantly to our further understanding of RAN's role in reading acquisition. 


\section{References}

Araújo, S., Reis, A., Petersson, K. M., \& Faísca, L. (2015). Rapid automatized naming and reading performance: A meta-analysis. Journal of Educational Psychology, 107, 868883. doi:10.1037/edu0000006.

Bond, G. L., \& Dijkstra, R. (1967). The cooperative research program in first-grade reading. Reading Research Quarterly, 2, 5-42. http://dx.doi.org/10.1598/RRQ.32.4.4

Borgwaldt, S. R., Hellwig, F. M., \& De Groot, A. M. B. (2005). Onset entropy matters Letter-to-phoneme mappings in seven languages. Reading and Writing 18, 211-229. Doi: I 10.1007/s11145-005-3001-9

Bowers, J. (1993). The syntax of predication. Linguistic Inquiry, 24, 591-656.

Bowers, P. G., \& Wolf, M. (1993). Theoretical links among naming speed, precise timing mechanisms and orthographic skill in dyslexia. Reading and Writing, an Interdisciplinary Journal, 5, 69-85. http://dx.doi.org/10.1007/BF01026919

Bowey, J. A. (2005). Predicting individual differences in learning to read. In M. J. Snowling \& C. Hulme (Eds.), The science of reading: A handbook (pp. 155-172). Oxford, England: Blackwell. http://dx.doi.org/10.1002/9780470757642.ch9/summary

Caravolas, M. (2005). The nature and causes of dyslexia in different languages. In M. J. Snowling \& C. Hulme (Eds.), The science of reading: A handbook (pp. 336-355). Malden, MA: Blackwell Publishing. http://dx.doi.org/10.1002/9780470757642.ch18/summary

Caravolas, M., \& Bruck, M. (1993). The effect of oral and written language input on children's phonological awareness: A cross-linguistic study. Journal of Experimental Child Psychology, 55, 1-30. http://dx.doi.org/10.1006/jecp.1993.1001 
Caravolas, M., Lervaag, A., Mousikou, P., Efrim, C., Litavsky, M., Onochie-Quintanlla, E., \& Et al. (2012). Common patterns of prediction of literacy development in different alphabetic orthographies. Psychological Science, 23, 678-686. http://dx.doi.org/0.1177/0956797611434536

Cardoso-Martins, C., \& Pennington, B. F. (2004). The relationship between phoneme awareness and rapid serial naming skills and literacy acquisition: The role of developmental period and reading ability. Scientific Studies of Reading, 8, 27-52. http://dx.doi.org/10.1207/s1532799xssr0801_3

Clarke, P., Hulme, C., \& Snowling, M. J. (2005). Individual differences in RAN and reading: A response timing analysis. Journal of Research in Reading, 28, 73-86. http://dx.doi.org/10.1111/j.1467-9817.2005.00255.x

Compton, D. L. (2003). Modeling the relationship between growth in rapid naming speed and growth in decoding skill in first-grade children. Journal of Educational Psychology, 95, 225-239. http://dx.doi.org/10.1037/0022-0663.95.2.225

Cummins, J. (1981). Bilingualism and minority language children. Ontario: Ontario Institute for Studies in Education.

Decker, S. L., Roberts, A. M., \& Englund, J. A. (2013). Cognitive predictors of rapid picture naming. Learning and Individual Differences, 25, 141-149.

Dunn, M., \& Dunn, L. M. (1997). Peabody Picture Vocabulary Test, Third Edition. Circle Pines, MN: American Guidance Service.

Dunn, M., \& Dunn, L.M. (1981). Peabody Picture Vocabulary Test-Revised. Circle Pines, MN : American Guidance Service.

Dunn, M., Thériault-Whalen, C. M., \& Dunn, L. M. (1993). Échelle de Vocabulaire en 
Images Peabody. Toronto: Psycan.

Ehri, L. C. (2005). Learning to read words: Theory, findings, and issues. Scientific Studies of Reading, 9, 167-188. http://dx.doi.org/10.1207/s1532799xssr0902_4

Erdos, C., Genesee, F., Savage, R. S., \& Haigh, C. (2014). Predicting risk for oral and written language learning difficulties in students educated in a second language. Applied Psycholinguistics, 35, 371-398. doi: 10.1017/S0142716412000422

Everatt, J., \& Zabell, C. (2002). Surface and phonological subtypes of adult developmental dyslexia. Dyslexia, 8, 160-177. http://dx.doi.org/10.1002/dys.223

Furnes, B., \& Samuelsson, S. (2011). Phonological awareness and rapid automatized naming predicting early development in reading and spelling: Results from a cross-linguistic longitudinal study. Learning and Individual Differences, 21, 85-95. http://dx.doi.org/10.1016/j.lindif.2010.10.005

Genesee, F. (2004). What do we know about bilingual education for majority language students. Handbook of bilingualism and multiculturalism, 547-576. http://dx.doi.org/10.1002/9780470756997.ch21

Georgiou, G. K., Parrila, R., Kirby, J. R., \& Stephenson, K. (2008). Rapid naming components and their relationship with phonological awareness, orthographic knowledge, speed of processing, and different reading outcomes. Scientific Studies of Reading, 12, 325-350. http://dx.doi.org/10.1080/10888430802378518

Georgiou, G. K., Parrilla, R., \& Kirby, J. (2006). Rapid naming speed components and early reading acquisition. Scientific Studies of Reading, 10, 199-220. http://dx.doi.org/10.1207/s1532799xssr1002_4

Georgiou, G., Manolitsis, G., Nurmi, J.-E., \& Parrila, R. (2010). Does task-focused versus 
task-avoidance behavior matter for literacy development in an orthographically consistent language? Contemporary Educational Psychology, 35, 1-10. http://dx.doi.org/10.1016/j.cedpsych.2009.07.001

Georgiou, G., Parilla, R., Cui, Y., \& Papadopoulos, T. C. (2013). Why is rapid automatized naming related to reading? Journal of Experimental Child Psychology, 115, 218-225. http://dx.doi.org/10.1016/j.jecp.2012.10.015

Haigh, C. A., Savage, R., Erdos, C., \& Genesee, F. (2011). The role of phoneme and onsetrime awareness in second language reading acquisition. Journal of Research in Reading, 34, 94-113. http://dx.doi.org/10.1111/j.1467-9817.2010.01475.x

Harris, H., \& Hatano, G. (1999). Learning to read and write: A cross-linguistic perspective. New York, NY: US Cambridge University Press.

Ibrahim, R. (2015). How does Rapid Automatized Naming (RAN) correlate with measures of reading fluency in Arabic. Psychology, 6, 269-277. http://dx.doi.org/10.4236/psych.2015.63027

Jared, D., Cormier, P., Levy, B. A., \& Wade-Woolley, L. (2013). Discrimination of English and French orthographic patterns by biliterate children. Journal of Experimental Child Psychology, 114, 469-488. http://dx.doi.org/10.1016/j.jecp.2012.11.001

Jared, D., Cormier, P., Levy, B. A., \& Wade-Woolley, L. (2011). Early predictors of biliteracy development in children in French immersion: A 4-year longitudinal study. Journal of Educational Psychology, 103, 119-139. http://dx.doi.org/10.1037/a0021284

Kail, R., Hall, L. K., \& Caskey, B. J. (1999). Processing speed, exposure to print, and naming speed. Applied Psycholinguistics, 20, 303-314. 
http://dx.doi.org/10.1017/S0142716499002076

Kirby, J. R., Georgiou, G. K., Martinussen, R., \& Parrila, R. (2010). Naming speed and reading: From prediction to instruction. Reading Research Quarterly, 45, 341-362. http://dx.doi.org/10.1598/RRQ.45.3.4

Kirby, J. R., Parrilla, R., \& Pfeiffer, S. L. (2003). Naming speed and phonological awareness as predictors of reading development. Journal of Educational Psychology, 95, 453464. http://dx.doi.org/10.1037/0022-0663.95.3.452

Landerl, K., \& Wimmer, H. (2000). Deficits in phoneme segmentation are not the core problem of dyslexia: Evidence from German and English children. Applied Psycholinguistics, 21, 243-262. http://dx.doi.org/10.1017/S0142716400002058

Landerl, K., \& Wimmer, H. (2008). Development of word reading fluency and spelling in a consistent orthography: An 8-year follow-up. Journal of Educational Psychology, 100, 150-161. http://dx.doi.org/10.1037/0022-0663.100.1.150

Lallier, M., Acha, J. and Carreiras, M. (2016). Cross-linguistic interactions influence reading development in bilinguals: a comparison between early balanced French-Basque and Spanish-Basque bilingual children. Developmental Science, 19, 76-89. doi:10.1111/desc. 12290

Lervåg, A., Bråten, I., \& Hulme, C. (2009). The cognitive and linguistic foundations of early reading development: A Norwegian latent variable longitudinal study. Developmental Psychology, 45, 764. http://dx.doi.org/10.1037/a0014132

Lervåg, A., \& Hulme, C. (2009). Rapid Automatized Naming (RAN) Taps a Mechanism That Places Constraints on the Development of Early Reading Fluency. Psychological Science, 20, 1040-1048. http://dx.doi.org/10.1111/j.1467-9280.2009.02405.x 
Manis, F. R., Seidenberg, M. S., \& Doi, L. M. (1999). See Dick RAN: Rapid naming and the longitudinal prediction of reading subskills in First and Second Graders. Scientific Studies of Reading, 3, 129-157. http://dx.doi.org/10.1207/s1532799xssr0302_3

Mann, V., \& Wimmer, H. (2002). Phoneme awareness and pathways into literacy: A comparison of German and American children. Reading and Writing, an Interdisciplinary Journal, 15, 653-682. http://dx.doi.org/10.1023/A:1020984704781

Meyer, M. S., Wood, F. B., Hart, L. A., \& Felton, R. H. (1998). Selective predictive value of rapid automatized naming in poor readers. Learning Disability Quarterly, 31, 106117.

Moll, K., Fussenegger, B., Willburger, E., \& Landerl, K. (2009). RAN is not a measure of orthographic processing. Evidence from the asymmetric German orthography. Scientific Studies of Reading, 13, 1-25. http://dx.doi.org/10.1080/10888430802631684

Moll, K. Ramus. F., Bartling, J., Bruder, J., Kunze, S., Neuhoff, N. et al. (2014). Cognitive mechanisms underlying reading and spelling development in five European orthographies. Learning and Instruction, 29, 65-77. http://dx.doi.org/10.1016/j.learninstruc.2013.09.003.

Morfidi, E., van der Leij, A., de Jong, P.F., Scheltinga, F., \& Bekebrede, J. (2007). Reading in two orthographies: A cross-linguistic study of Dutch average and poor readers who learn English as a second language. Reading and Writing, 20, 753-784.

Norton, E. S., \& Wolf, M. (2012). Rapid Automatized Naming (RAN) and reading fluency: Implications for understanding and treatment of reading disabilities. Annual Review of Psychology, 63, 427-452. http://dx.doi.org/10.1146/annurev-psych-120710-100431 
Patel, T. K., Snowling, M. J., \& De Jong, P. F. (2004). A cross-linguistic comparison of children learning to read in English and Dutch. Journal of Educational Psychology, 96, 785-797. http://dx.doi.org/10.1037/0022-0663.96.4.785

Powell, D., Stainthorp, R., \& Stuart, M. (2014). Deficits in orthographic knowledge in children poor at rapid automatized naming (RAN) tasks? Scientific Studies of Reading, 18, 192-207. http://dx.doi.org/10.1080/10888438.2013.862249

Raven, J., Raven, J. C., \& Court, J. H. (1998). Manual for Raven's Progressive Matrices and Vocabulary Scales. Section 2: The Coloured Progressive Matrices. San Antonio, TX: Harcourt Assessment.

Savage, R.S., \& Frederickson, N. (2005). Evidence of a highly specific relationship between rapid automatic naming of digits and text-reading speed. Brain \& Language, 93, 152159. http://dx.doi.org/10.1016/j.bandl.2004.09.005

Savage, R. S. (2004). Motor skills, Automaticity, and Developmental Dyslexia: A review of the research literature. Reading and Writing: An Interdisciplinary Journal, 17, 301324. http://dx.doi.org/10.1023/B:READ.0000017688.67137.80

Savage, R. S., Pillay, V., \& Melidona, S. (2007). Deconstructing rapid automatised naming: Component processes and the prediction of reading difficulties. Learning and Individual Differences, 17, 129 - 146.

Schatschneider, C., Fletcher, J. M., Francis, D. J., Carlson, C., \& Foorman, B. R. (2004). Kindergarten prediction of reading skills: A longitudinal comparative analysis. Journal of Educational Psychology, 96, 265-282. http://dx.doi.org/10.1037/0022$\underline{0663.96 .2 .265}$

Schmalz, X., Marinus, E., Coltheart, M., \& Castles, A. (2015). Getting to the bottom of 
orthographic depth. Psychonomic Bulletin Review.

doi 10.3758/s13423-015-0835-2

Seymour, P. H., Aro, M., \& Erskine, J. M. (2003). Foundation literacy acquisition in European orthographies. British Journal of Psychology, 94, 143-174. http://dx.doi.org/10.1348/000712603321661859

Share, D. (2008). On the anglocentricities of current reading research and practice: The perils of overreliance on an outlier', orthography. Psychological Bulletin, 134, 584-615. http://dx.doi.org/10.1037/0033-2909.134.4.584

Share, D. L. (1995). Phonological recoding and self-teaching: Sine qua non of reading acquisition. Cognition, 55, 151-218. http://dx.doi.org/10.1016/0010-0277(94)00645-2

Snowling, M. J., \& Hulme, C. (1994). The development of phonological skills. Philosophical Transactions of the Royal Society B-Biological Sciences, 346, 21-28. http://dx.doi.org/10.1098/rstb.1994.0124

Song, S., Georgiou, G., Su, M., \& Hua, S. (2016). How well do phonological awareness and rapid automatized naming correlate with Chinese reading accuracy and fluency? A meta-analysis. Scientific Studies of Reading, 20, 99-123. Http://dx.doi.org/10. 1080/10888438.2015.1088543. http://dx.doi.org/10.1080/10888438.2015.1088543

Stainthorp, R. W., Stuart, M., Powell, D., Quinlan, P., \& Garwood, H. (2010). Visual processing deficits in children with slow RAN performance. Scientific Studies of Reading, 14, 266-292. http://dx.doi.org/10.1080/10888431003724070

Torgesen, J. K., Wagner, R. K., \& Rashotte, C. A. (1997). Prevention and remediation of severe reading disabilities: Keeping the end in mind. Scientific Studies of Reading, 1, 217-234. http://dx.doi.org/10.1207/s1532799xssr0103_3 
Torgesen, J. K., Wagner, R. K., \& Rashotte, C. A. (1999). Test of Word Reading Efficiency. Austin, TX: PRO-ED Publishing, Inc.

Torgesen, J.K., Wagner, R.K., Rashotte, C.A., Burgess, S., \& Hecht, S. (1997). Contributions of phonological awareness and rapid automatic naming ability to the growth of wordreading skills in second- to fifth-grade children. Scientific Studies of Reading, 1(2), 161-195.

Van den Boer, M., De Jong, P. F., \& Haentjens-van Meeteren, M. M. (2013). Modeling the length effect: Specifying the relation with visual and phonological correlates of reading. Scientific Studies of Reading, 17, 243-356.

http://dx.doi.org/10.1080/10888438.2012.683222

Vaessen, A., Tóth, D., Csépe. V., Bertrand, D., Faísca, L., Reis, A., et al. (2010). Cognitive development of fluent word reading does not qualitatively differ between transparent and opaque orthographies Journal of Educational Psychology, 102, 827-842. doi: $10.1037 / \mathrm{a} 0019465$

Wagner, R. K., \& Torgesen, J. K. (1987). The nature of phonological processing and its causal role in the acquisition of reading skills. Psychological Bulletin, 101, 192-212. http://dx.doi.org/10.1037//0033-2909.101.2.192

Wagner, R. K., Torgesen, J. K., Rashotte, C. A., Hecht, S. A., Barker, T. A., Burgess, S. R., \& Garon, T. (1997). Changing relations between phonological processing abilities and word-level reading as children develop from beginning to skilled readers: A 5-year longitudinal study. Developmental Psychology, 33, 468-479. http://dx.doi.org/10.1037/0012-1649.33.3.468 
Wilkinson, G. S. (1993). WRAT3: Wide Range Achievement Test Administration Manual. Wide Range, Inc. 15 Ashley Place, Suite 1A. Wilmington, DE

Wimmer, H. (1993). Characteristics of developmental dyslexia in a regular writing system. Applied Psycholinguistics, 14, 1-33. http://dx.doi.org/10.1017/S0142716400010122

Wimmer, H., Mayringer, H., \& Landerl, K. (1998). Poor reading: A deficit in skillautomatization or a phonological deficit? Scientific Studies of Reading, 2, 321-340. http://dx.doi.org/10.1207/s1532799xssr0204_2

Wolf, M., \& Bowers, P. G. (1999). The double-deficit hypothesis for the developmental dyslexias. Journal of Educational Psychology, 91, 415-438. http://dx.doi.org/10.1037/0022-0663.91.3.415

Wolf, M., \& Denckla, M. B. (2005). Rapid Automatized Naming and Rapid Alternating Stimulus tests. Austin, TX: Pro-Ed.

Young, A., \& Bowers, P. G. (1995). Individual differences and text difficulty determinants of reading fluency and expressiveness. Journal of Experimental Child Psychology, 60, 428-454. http://dx.doi.org/10.1006/jecp.1995.1048

Ziegler, J. C., Bertrand, D., Tóth, D., Csépe, V., Reis, A., Faísca, L.,... Blomert, L. (2010). Orthographic depth and its impact on universal predictors of reading: A crosslanguage investigation. Psychological Science, 21, 551-559. 


\section{Acknowledgments}

This work was funded by the Social Sciences and Humanities Research Council of Canada.

i As we seek to focus on orthographic and phonological processes in the present paper we elect to exemplify these using a dual route approach. Seidenberg and McClelland's (1989) triangle theory provides a strong alternative to the dual route model but assumes an as yet unimplemented, semantic influence. Semantics is beyond the scope of the present paper. 
Table 1

Inter-correlations between French predictors and French reading outcomes / English predictors and English outcome measures

\begin{tabular}{|c|c|c|c|c|c|c|c|c|c|c|c|c|c|c|c|}
\hline & 1 & 2 & 3 & 4 & 5 & 6 & 7 & 8 & 9 & 10 & 11 & 12 & 13 & 14 & 15 \\
\hline $\begin{array}{l}1 . \\
\text { EVIP/ } \\
\text { PPVT }\end{array}$ & - & .209 & $\begin{array}{c}.13 \\
4\end{array}$ & $\begin{array}{c}.313^{*} \\
*\end{array}$ & $.230^{*}$ & $\begin{array}{c}- \\
.253^{*}\end{array}$ & -.082 & -.132 & -.203 & $.259^{*}$ & .221 & .188 & .210 & $\begin{array}{c}.359^{*} \\
*\end{array}$ & .146 \\
\hline $\begin{array}{l}2 . \\
\text { Rave } \\
n\end{array}$ & -.169 & - & $\begin{array}{c}- \\
.00 \\
6\end{array}$ & .056 & .071 & -.012 & .050 & .053 & -.074 & .087 & .070 & -.017 & .093 & .067 & .066 \\
\hline $\begin{array}{l}\text { 3. Sk } \\
\text { age }\end{array}$ & .128 & .006 & - & .136 & -.026 & -.082 & -.067 & -.153 & .087 & .140 & .112 & .088 & .104 & .200 & .120 \\
\hline $\begin{array}{l}4 . \\
\text { Blend }\end{array}$ & -.201 & .097 & $\begin{array}{c}.13 \\
2\end{array}$ & - & $\begin{array}{c}.507 * \\
*\end{array}$ & -.129 & -.020 & -.136 & -.198 & $\begin{array}{c}.521 * \\
*\end{array}$ & $\begin{array}{c}.527^{*} \\
*\end{array}$ & $\begin{array}{c}.407 * \\
*\end{array}$ & $\begin{array}{c}.463^{*} \\
*\end{array}$ & $\begin{array}{c}.436 * \\
*\end{array}$ & $\begin{array}{c}.416^{*} \\
*\end{array}$ \\
\hline $\begin{array}{l}5 . \\
\text { WRA } \\
T\end{array}$ & .122 & .019 & $\begin{array}{c}.07 \\
0\end{array}$ & $\begin{array}{c}.609 * \\
*\end{array}$ & - & -.174 & -.100 & $\begin{array}{c}- \\
.258^{*}\end{array}$ & $\begin{array}{c}- \\
.346^{*} \\
*\end{array}$ & $\begin{array}{c}.472^{*} \\
*\end{array}$ & $\begin{array}{c}.478^{*} \\
*\end{array}$ & $\begin{array}{c}.396^{*} \\
*\end{array}$ & $\begin{array}{c}.412 * \\
*\end{array}$ & $\begin{array}{c}.346^{*} \\
*\end{array}$ & $\begin{array}{c}.336^{*} \\
*\end{array}$ \\
\hline $\begin{array}{l}6 . \\
\text { RAN } \\
\text { O }\end{array}$ & $\begin{array}{c}- \\
.267 *\end{array}$ & $\begin{array}{c}- \\
.008\end{array}$ & $\begin{array}{c}- \\
.06 \\
5\end{array}$ & -.124 & $\begin{array}{c}- \\
.313^{*} \\
*\end{array}$ & - & $\begin{array}{c}.755^{*} \\
*\end{array}$ & $\begin{array}{c}.678^{*} \\
*\end{array}$ & $\begin{array}{c}.763 * \\
*\end{array}$ & $\begin{array}{c}- \\
.296^{*} \\
*\end{array}$ & ${ }^{-} \cdot 3^{*}$ & $\begin{array}{c}- \\
.353^{*} \\
*\end{array}$ & $\begin{array}{c}- \\
.284 *\end{array}$ & $\begin{array}{c}- \\
.432 * \\
*\end{array}$ & $\begin{array}{c}- \\
.267 *\end{array}$ \\
\hline $\begin{array}{l}7 . \\
\text { RAN } \\
\text { C }\end{array}$ & -.247 & $\begin{array}{c}- \\
.278 \\
*\end{array}$ & $\begin{array}{c}- \\
.10 \\
1\end{array}$ & .019 & 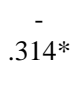 & $\begin{array}{c}.684^{*} \\
*\end{array}$ & - & $\begin{array}{c}.696^{*} \\
*\end{array}$ & $\begin{array}{c}.731 * \\
*\end{array}$ & -.174 & -.113 & -.198 & -.130 & $\begin{array}{c}- \\
.315^{*} \\
*\end{array}$ & -.126 \\
\hline $\begin{array}{l}8 . \\
\text { RAN } \\
N\end{array}$ & -.229 & .091 & $\begin{array}{c}- \\
.16 \\
2\end{array}$ & -.098 & $\begin{array}{c}- \\
.402 * \\
*\end{array}$ & $\begin{array}{c}.762 * \\
*\end{array}$ & $\begin{array}{c}.698^{*} \\
*\end{array}$ & - & $\begin{array}{c}.824 * \\
*\end{array}$ & $\begin{array}{c}- \\
.420^{*} \\
*\end{array}$ & $\stackrel{-}{-} .303^{*}$ & $\begin{array}{c}- \\
.450^{*} \\
*\end{array}$ & $\begin{array}{c}- \\
.326^{*} \\
*\end{array}$ & $\begin{array}{c}- \\
.499^{*} \\
*\end{array}$ & $\begin{array}{c}- \\
.355^{*} \\
*\end{array}$ \\
\hline $\begin{array}{l}9 . \\
\text { RAN } \\
\text { L }\end{array}$ & -.116 & $\begin{array}{c}- \\
.061\end{array}$ & $\begin{array}{c}- \\
.03 \\
8\end{array}$ & -.221 & $\begin{array}{c}- \\
.448 *\end{array}$ & $\begin{array}{c}.729 * \\
*\end{array}$ & $\begin{array}{c}.665^{*} \\
*\end{array}$ & $\begin{array}{c}.802 * \\
*\end{array}$ & - & $\stackrel{-}{.} 308^{*}$ & $.285^{-}$ & $\begin{array}{c}- \\
.298^{*}\end{array}$ & $\begin{array}{c}- \\
.263^{*}\end{array}$ & $\begin{array}{c}- \\
.431 * \\
*\end{array}$ & $.280^{-}$ \\
\hline $\begin{array}{l}10 . \\
\text { G2 T } \\
w\end{array}$ & $.256^{*}$ &. & $\begin{array}{c}.11 \\
8\end{array}$ & $\begin{array}{c}.329 * \\
*\end{array}$ & $\begin{array}{c}.651^{*} \\
*\end{array}$ & $\begin{array}{c}- \\
.497 * \\
*\end{array}$ & $\begin{array}{c}- \\
.487 * \\
*\end{array}$ & $\begin{array}{c}- \\
.501 * \\
*\end{array}$ & $\begin{array}{c}- \\
.554^{*} \\
*\end{array}$ & - & $\begin{array}{c}.874 * \\
*\end{array}$ & $\begin{array}{c}.907 * \\
*\end{array}$ & $\begin{array}{c}.849 * \\
*\end{array}$ & $\begin{array}{c}.771 * \\
*\end{array}$ & $\begin{array}{c}.809^{*} \\
*\end{array}$ \\
\hline $\begin{array}{l}11 . \\
\text { G2 T } \\
\text { pw }\end{array}$ & .193 & .134 & $\begin{array}{c}.16 \\
8\end{array}$ & .221 & $\begin{array}{c}.526^{*} \\
*\end{array}$ & $\begin{array}{c}- \\
.371 * \\
*\end{array}$ & $\begin{array}{c}- \\
.400 * \\
*\end{array}$ & $\begin{array}{c}- \\
.364^{*} \\
*\end{array}$ & $\begin{array}{c}- \\
.504 * \\
*\end{array}$ & $\begin{array}{c}.864 * \\
*\end{array}$ & - & $\begin{array}{c}.777 * \\
*\end{array}$ & $\begin{array}{c}.803 * \\
*\end{array}$ & $\begin{array}{c}.634^{*} \\
*\end{array}$ & $\begin{array}{c}.720 * \\
*\end{array}$ \\
\hline $\begin{array}{l}12 . \\
\text { G3 T } \\
\text { w }\end{array}$ & $\begin{array}{c}.294 * \\
*\end{array}$ & $\begin{array}{c}- \\
.059\end{array}$ & $\begin{array}{c}.04 \\
4\end{array}$ & $.277 *$ & $\begin{array}{c}.548^{*} \\
*\end{array}$ & $\begin{array}{c}- \\
.486^{*} \\
*\end{array}$ & $\begin{array}{c}- \\
.493 * \\
*\end{array}$ & $\begin{array}{c}- \\
.539 * \\
*\end{array}$ & $\begin{array}{c}- \\
.502 * \\
*\end{array}$ & $\begin{array}{c}.878^{*} \\
*\end{array}$ & $\begin{array}{c}.802 * \\
*\end{array}$ & - & $\begin{array}{c}.857 * \\
*\end{array}$ & $\begin{array}{c}.778^{*} \\
*\end{array}$ & $\begin{array}{c}.795^{*} \\
*\end{array}$ \\
\hline $\begin{array}{l}13 . \\
\text { G3 T } \\
\text { pw }\end{array}$ & .178 & .049 & $\begin{array}{c}.08 \\
3\end{array}$ & $.234^{*}$ & $\begin{array}{c}.542 * \\
*\end{array}$ & $\begin{array}{c}- \\
.415^{*} \\
*\end{array}$ & $\begin{array}{c}- \\
.363 * \\
*\end{array}$ & $\begin{array}{c}- \\
.399 * \\
*\end{array}$ & $\begin{array}{c}- \\
.453 * \\
*\end{array}$ & $\begin{array}{c}.843 * \\
*\end{array}$ & $\begin{array}{c}.846^{*} \\
*\end{array}$ & $\begin{array}{c}.869^{*} \\
*\end{array}$ & - & $\begin{array}{c}.707 * \\
*\end{array}$ & $\begin{array}{c}.766^{*} \\
*\end{array}$ \\
\hline $\begin{array}{l}14 . \\
\text { G6 T } \\
w\end{array}$ & $\begin{array}{c}.309 * \\
*\end{array}$ & .025 & $\begin{array}{c}.03 \\
2\end{array}$ & $.241 *$ & $\begin{array}{c}.537 * \\
*\end{array}$ & $\begin{array}{c}- \\
.478^{*} \\
*\end{array}$ & $\begin{array}{c}- \\
.510^{*} \\
*\end{array}$ & $\begin{array}{c}- \\
.553 * \\
*\end{array}$ & $\begin{array}{c}- \\
.561 * \\
*\end{array}$ & $\begin{array}{c}.817^{*} \\
*\end{array}$ & $\begin{array}{c}.758^{*} \\
*\end{array}$ & $\begin{array}{c}.850^{*} \\
*\end{array}$ & $\begin{array}{c}.767 * \\
*\end{array}$ & - & $\begin{array}{c}.785^{*} \\
*\end{array}$ \\
\hline $\begin{array}{l}15 . \\
\text { G6 T } \\
\text { pw }\end{array}$ & $\begin{array}{c}.233 * \\
*\end{array}$ & .004 & $\begin{array}{c}.18 \\
4\end{array}$ & $\begin{array}{c}.323 * \\
*\end{array}$ & $\begin{array}{c}.472 * \\
*\end{array}$ & $\begin{array}{c}- \\
.403^{*} \\
*\end{array}$ & $\begin{array}{c}- \\
.405^{*} \\
*\end{array}$ & $\begin{array}{c}- \\
.446^{*} \\
*\end{array}$ & $\begin{array}{c}- \\
.554 * \\
*\end{array}$ & $\begin{array}{c}.765^{*} \\
*\end{array}$ & $\begin{array}{c}.793^{*} \\
*\end{array}$ & $\begin{array}{c}.733 * \\
*\end{array}$ & $\begin{array}{c}.778^{*} \\
*\end{array}$ & $\begin{array}{c}.672^{*} \\
*\end{array}$ & - \\
\hline
\end{tabular}

Notes. $* p<.05 ; * * p<.01$. When available, standard scores were entered for descriptive statistics (Fk PPVT, Fk EVIP, Sk E WRAT, ERAN O/C/N/L/L, N/L, N, C, G2/3/6 E T w/pw). In other cases, raw scores were used. English correlations are presented in the upper triangle, French in the lower triangle

Key:

EVIP / PPVT-3: Fall kindergarten score on the French / English version of the Peabody Picture Vocabulary Test (EVIP/PPVT-3)

Raven: Fall kindergarten score on Raven's progressive matrices

Sk age: Age in the spring of kindergarten

Blend: Spring kindergarten score on French / English blending out of 27

WRAT-3: Spring kindergarten score on the French / English version of the word reading subtest of the Wide Range Achievement Test-3 (WRAT-3) 
RAN O: Spring kindergarten score on the objects subtest of the French / English Rapid Automatic Naming and Rapid Alternating Stimulus Tests (RAN/RAS)

RAN C: Spring kindergarten score on the colors subtest of the French / English RAN/RAS tests

RAN N: Spring kindergarten score on the numbers subtest of the French / English RAN/RAS tests

RAN L: Spring kindergarten score on the letters subtest of the French / English RAN/RAS tests

G2 T w: Grade 2 score on the word reading subtest of the French / English Test of Word Reading Efficiency (TOWRE)

G2 T pw: Grade 2 score on the pseudoword reading subtest of the French / English TOWRE

G3 T w: Grade 3 score on the word reading subtest of the French / English TOWRE

G3 T pw: Grade 3 score on the pseudoword reading subtest of the French / English TOWRE

G6 T w: Grade 6 score on the word reading subtest of the French / English TOWRE

G6 T pw: Grade 6 score on the pseudoword reading subtest of the French / English TOWRE 
Table 2

Descriptive statistics and reliability measures for all predictor and outcome measures

\begin{tabular}{|c|c|c|c|c|c|}
\hline & \multicolumn{2}{|c|}{ Raw score } & \multicolumn{2}{|c|}{ Standard score } & \multirow{2}{*}{$\begin{array}{c}\text { Reliability } \\
\text { (r) }\end{array}$} \\
\hline & $M$ & $S D$ & $M$ & $S D$ & \\
\hline Fall K PPVT-3 & 79.94 & 14.94 & 106.05 & 11.86 & .94 \\
\hline Fall K EVIP & 28.39 & 20.16 & 73.10 & 19.63 & .82 \\
\hline Fall K English WRAT-3 & 11.30 & 5.23 & 98.52 & 16.40 & $.92-.96$ \\
\hline Fall K French WRAT-3 & .26 & 1.21 & & & .85 \\
\hline Fall K RAVEN's & 18.39 & 4.09 & & & .88 \\
\hline Spring $\mathrm{K}$ age (months) on CELF-4 & 71.18 & 3.49 & & & \\
\hline Spring K English blending total out of 27 & 12.68 & 10.30 & & & .89 \\
\hline Spring K French blending total out of 27 & 10.68 & 9.78 & & & .92 \\
\hline Spring K English RAN/RAS objects & 68.32 & 19.58 & 99.88 & 15.67 & $.81-.89$ \\
\hline Spring K English RAN/RAS colours & 74.35 & 38.59 & 98.06 & 16.94 & $.81-.89$ \\
\hline Spring K English RAN/RAS numbers & 62.96 & 25.61 & 98.49 & 15.21 & $.81-.89$ \\
\hline Spring K English RAN/RAS letters & 68.74 & 28.41 & 98.48 & 15.49 & $.81-.89$ \\
\hline Spring K French RAN/RAS objects & 88.46 & 33.72 & & & \\
\hline Spring K French RAN/RAS colours & 86.87 & 30.21 & & & \\
\hline Spring K French RAN/RAS numbers & 76.44 & 35.91 & & & \\
\hline Spring K French RAN/RAS letters & 69.71 & 31.59 & & & \\
\hline Grade 2 English TOWRE words & 48.84 & 17.31 & 101.58 & 15.36 & $.92-.97$ \\
\hline Grade 2 English TOWRE pseudo-words & 23.83 & 12.55 & 100.82 & 24.40 & $.90-.97$ \\
\hline Grade 2 French TOWRE words & 53.29 & 14.16 & & & $.77-.87$ \\
\hline Grade 2 French TOWRE pseudo-words & 31.34 & 12.22 & & & $.77-.87$ \\
\hline Grade 3 English TOWRE words & 63.66 & 14.05 & 107.84 & 15.85 & $.92-.97$ \\
\hline Grade 3 English TOWRE pseudo-words & 34.49 & 13.65 & 108.75 & 16.68 & $.90-.97$ \\
\hline Grade 3 French TOWRE words & 62.19 & 13.62 & & & $.77-.87$ \\
\hline Grade 3 French TOWRE pseudo-words & 38.60 & 12.30 & 38.60 & & $.77-.87$ \\
\hline Grade 6 English TOWRE words & 77.40 & 11.12 & 106.58 & 12.40 & $.92-.97$ \\
\hline Grade 6 English TOWRE pseudo-words & 45.39 & 10.72 & 110.78 & 13.94 & $.90-.97$ \\
\hline Grade 6 French TOWRE words & 75.45 & 13.87 & 105.73 & 14.67 & $.77-.87$ \\
\hline Grade 6 French TOWRE pseudo-words & 47.23 & 10.25 & 113.45 & 14.00 & $.77-.87$ \\
\hline
\end{tabular}

Note: For standard scores mean $=100, S D=15$. 
Table 3

Regression analyses exploring English (E) predictors of English reading fluency

\begin{tabular}{|c|c|c|c|c|c|c|}
\hline Dependent variable & Grade 2 & & Grade 3 & & Grade 6 & \\
\hline A. Pseudoword Reading Fluency & $R^{2}$ chang & $\beta$ & $R^{2}$ & $\beta$ & $R^{2}$ & $\beta$ \\
\hline 1) Step 1 combined effect & $.313 * * *$ & & $.255^{* * *}$ & & $.205^{* *}$ & \\
\hline 2) Latent E RAN variable & .022 & -.155 & .031 & -.185 & .036 & -.199 \\
\hline B. Word Reading Fluency & & & & & & \\
\hline 1) Step 1 combined effect & $.326 * * *$ & & $.220 * *$ & & $.292 * * *$ & \\
\hline 2) Latent E RAN variable & .036 & -.199 & $.057^{*}$ & $-.249 *$ & $.104 * *$ & $-.338 * *$ \\
\hline $\begin{array}{l}\text { C. Word Reading Fluency } \\
\text { (controlling pseudoword fluency) }\end{array}$ & & & & & & \\
\hline 1) Step 1 combined effect & $.326 * * *$ & & $.220 * *$ & & $.292 * * *$ & \\
\hline 2) Pseudoword reading & $.456 * * *$ & $.814 * * *$ & $.525 * * *$ & $.840 * * *$ & $.405^{* * *}$ & $.714 * * *$ \\
\hline 3) Latent E RAN variable & .005 & -.076 & .008 & -.098 & $.037 * *$ & $-.206 * *$ \\
\hline
\end{tabular}

Note. $* p<.05 ; * * p<.01 ; * * * p<.001$. 
Table 4

Regression analyses exploring French $(\mathrm{F})$ predictors of French reading fluency

\begin{tabular}{|c|c|c|c|c|c|c|}
\hline Dependent variable & Grade 2 & & Grade 3 & & Grade 6 & \\
\hline A. Pseudoword Reading Fluency & $\begin{array}{l}R^{2} \\
\text { change }\end{array}$ & $\beta$ & $\begin{array}{l}R^{2} \\
\text { change }\end{array}$ & $\beta$ & $\begin{array}{l}R^{2} \\
\text { change }\end{array}$ & $\beta$ \\
\hline 1) Step 1 combined effect & $.189 *$ & & $.174 *$ & & $.222 * *$ & \\
\hline 2) Latent F RAN variable & $.073 *$ & $-.297 *$ & $.067 *$ & $-.283 * *$ & $.082 * *$ & $-.314 * *$ \\
\hline \multicolumn{7}{|l|}{ B. Word Reading Fluency } \\
\hline 1) Step 1 combined effect & $.310 * * *$ & & $.308 * * *$ & & $.214 * *$ & \\
\hline 2) Latent F RAN variable & $.087 * *$ & $-.323 * *$ & $.091 * *$ & $-.331 * *$ & $.117 * *$ & $-.375^{* *}$ \\
\hline \multicolumn{7}{|l|}{$\begin{array}{l}\text { C. Word Reading Fluency } \\
\text { (controlling pseudoword fluency) }\end{array}$} \\
\hline 1) Step 1 combined effect & $.310 * * *$ & & $.308 * * *$ & & $.214 * *$ & \\
\hline 2) Pseudoword reading & $.514 * * *$ & $.796^{* * * *}$ & $.507 * * *$ & $.783 * * *$ & $.253^{* * * *}$ & $.571 * * *$ \\
\hline \multicolumn{7}{|l|}{ fluency } \\
\hline 3) Latent F RAN variable & .007 & -.095 & $.011^{*}$ & $-.119 *$ & $.036^{*}$ & $-.219^{*}$ \\
\hline
\end{tabular}

Note. $* p<.05 ; * * p<.01 ; * * * p<.001$. 
Table 5

Regression analyses exploring English (E) predictors of French reading fluency

\begin{tabular}{cccccccc}
\hline \multicolumn{2}{l}{$\begin{array}{l}\text { Dependent variable } \\
\text { A. Pseudo-word Reading Fluency }\end{array}$} & \begin{tabular}{c} 
Grade 2 \\
\cline { 2 - 7 } \\
change
\end{tabular} & $\beta$ & $\begin{array}{c}R^{2} \\
\text { change }\end{array}$ & $\beta$ & $\begin{array}{c}R^{2} \\
\text { change }\end{array}$ & $\beta$ \\
\hline 1) Step 1 combined effect & $.220^{*}$ & & .158 & & $.190^{*}$ \\
& & $.060^{*}$ & $-.258^{*}$ & .037 & -.202 & .038 & -.206
\end{tabular}

B. Word Reading Fluency

1) Step 1 combined effect

$.188^{*}$

.155

.092

2) Latent E RAN variable

$.048 \quad-.230$

$.033 \quad-.192$

$.095^{*}$

$-.325^{*}$

C. Word Reading Fluency (controlling pseudo-word fluency)

1) Step 1 combined effect

.092

2) Pseudo-word reading

$.541 * * *$

$.832 * * *$

$.615 * * *$

$.855^{* * *}$

$.227 * * *$

$.529 * * *$ fluency

3) Latent E RAN variable

.000

$-.017$

.000

$-.021$

.044

$-.227$

Note. $* p<.05 ; * * p<.01 ; * * * p<.001$. 